\title{
Development of recent faulting in the southern Dead Sea Rift according to GPR imaging
}

\author{
U. Basson ${ }^{1}$, Z. Ben-Avraham ${ }^{1}$, Z. Garfunkel ${ }^{2}$, and V. Lyakhovsky ${ }^{3}$ \\ ${ }^{1}$ Department of Geophysics and Planetary Sciences, Tel-Aviv University, Ramat Aviv, Tel Aviv 69978, Israel \\ ${ }^{2}$ Institute of Earth Sciences, Hebrew University, Jerusalem 91905, Israel \\ ${ }^{3}$ Geological Survey of Israel, 30 Malkhei Israel, Jerusalem 95501, Israel
}

Received: 3 January 2002 - Revised: 8 April 2002 - Accepted: 7 May 2002

\begin{abstract}
The Arava valley is located at the southern part of the Dead Sea Rift (DSR). The continuous long-term tectonic activity in the area of Evrona fault zone, southern Arava valley, is evident with abundant geological expressions, while the neotectonic activity is not very clear on the surface. Furthermore, surficial inspection may give the impression that this prominent transform plate-boundary hardly produces meaningful evidence for recent tectonic activity.

However, Ground Penetrating Radar (GPR) imaging, which has been conducted across the Evrona fault zone up to a depth of approximately 25 meters below the surface, reveals a dense inhomogeneous distribution of subsurface discontinuities. These hundreds of discontinuities per a kilometer length of GPR profile can be interpreted as sets of fractures and faults, with a variety of dip-slips, spatial orientations and depths. Another unique GPR observation reveals that the density of faults increases as a function of depth at the first $25 \mathrm{~m}$. Moreover, the apparent dips of the faults suggest that they merge at a depth of a few tens of meters. This is confirmed by Shallow Seismic Reflection (SSR) observations conducted at the same locations, which generally identify a parent fault below group of faults that are detected by the GPR. According to both seismic and radar observations, a typical single active fault which is traced through the top hundred meters, changes its characteristics abruptly as it reaches a depth range of about 35-20 m below the surface. It then proceeds towards the surface in a series of splays. As a result of this mechanism, the tectonic displacement that accumulates along a plane of a parent fault is dispersed towards the surface. Linear Shear Strength Decrease (LSSD), damage distribution and fault propagation modelling of the relations between the structure and distribution of the faults and the mechanical properties of the alluvial materials of Evrona emphasize the splay mechanism and other phenomena revealed by the GPR images.
\end{abstract}

Correspondence to: U. Basson (uri@geo-sense.com)
An analysis of the faults detected by GPR in Evrona helped in evaluating the relative level of tectonic activity of an active fault zone. According to this approach, the neotectonic history of the Evrona fault zone during the last $45000 \mathrm{yr}$ is recorded. The GPR record reveals a peak in tectonic activity within $18000-27000 \mathrm{ybp}$. This peak in tectonic activity is about $37 \%$ higher than the average tectonic activity of the whole period. The level of tectonic activity in the recent period recorded by GPR (0-9000 ybp) is about $70 \%$ of the average tectonic activity and about $50 \%$ of the peak activity. These values and the decreasing trend in the tectonic activity since the peak wave suggest that the most recent period is tectonically quiet.

\section{Introduction}

Israel is located in a seismically active region, where earthquakes are triggered mostly by plate motion along the transform boundary of the Dead Sea Rift (DSR) (Fig. 1a, after Bartov, 1990). The DSR is one of the most conspicuous geologic features in the Middle East, with a total left lateral slip of $105 \mathrm{~km}$ accumulated since Middle Miocene (ca. 17$20 \mathrm{Ma}$ ) (Quennell, 1959; Freund et al., 1970; Bartov, 1974; Steinitz et al., 1978; Garfunkel, 1981; Bandel and Khouri, 1981; Joffe and Garfunkel, 1987). According to these values, the average motion along the transform boundary is about 5$6 \mathrm{~mm} / \mathrm{yr}$.

The Evrona fault, which is a prominent left-lateral strike slip-fault of the DSR extends along the northwest part of the Gulf of Elat (Aqaba), from the Gulf's head across the coastline to the sedimentary basins of the southern Arava valley (Ben-Avraham et al., 1979a, b; Ben-Avraham, 1985; Reches et al., 1987; Ben-Avraham (1992); Ben-Avraham and Zoback (1992); Ben-Avraham and Tibor, 1993; Shamir, 1996; Galli, P., 1999; Fig. 1b). On land, it crosses the Elat sabkha, the 
Evrona playa and the eastern part of the Yotveta playa (Zak and Freund, 1966; Garfunkel, 1969, 1970, 1981; Garfunkel et al., 1981).

The studied portion of the Evrona fault, which includes the Evrona playa in its center, is located about $10-15 \mathrm{~km}$ north of the Gulf of Elat (Aqaba) (Fig. 1b). The youngest surface ruptures, which were detected and mapped by Garfunkel $(1969,1970)$, were recently found to be part of a broad zone of shearing, concealing a range of shallow recent active faults that are partially revealed on land as fault scarps and lineament structures (similar to other broad shear zones observed in unconsolidated deposits, compact and loose alluvium) (Johnson et al., 1993, 1994; Lazarte et al., 1994).

The purpose of this study was to investigate the shallow subsurface rupture structure of the Evrona fault zone in order to understand the pattern of faulting and the fault zone mechanisms. The study addresses several questions: Does the surficial rupture reflect the subsurface rupturing? What is the structure and the distribution of faults across the Evrona fault zone, as a function of location and depth? Does the broad Evrona shear zone consist of distinct belts of shear zones? How does the shallow structure of faulting reflect the mechanism of faulting at depth?

During the study, results of Ground Penetrating Radar (GPR), were integrated with results of Shallow Seismic Reflection (SSR) and trenching. More than $20 \mathrm{~km}$ of highresolution GPR profiles were collected, processed and analyzed. As a result, the study presents a unique documentation of shallow subsurface rupture structures through ca. 45000 years of tectonic activity, as revealed by high-resolution GPR profiles. The study reveals the shallow subsurface in the Evrona fault zone, presenting its diffused faulting characteristics. It shows that the shallow structure, mapped by GPR, contains a significant geological record of recent faulting activity that is far more extensive than previously documented. The shallow fault structure observed during the field study was compared with the results of numerical simulations that allow examining the faulting mechanism within the top $100 \mathrm{~m}$ of the Evrona fault zone.

\section{The southern Arava valley}

The southern Arava valley, bordered by relatively high mountains to the east and west is a distinct morphological unit of the DSR (Garfunkel, 1970; Gerson and Grossman, 1991; Fig. 1b). The difference between the two margins of the southern Arava valley and the variability in lithology, structure and geomorphic features are remarkable due to the large horizontal displacement along the strike-slip of the DSR. Surficial features were formed under a varying arid climate. During most of the Quarternary the region experienced a mild to extremely arid climate; at present, the climate is extremely arid. The margins of the Arava valley are bordered by large alluvial fans formed mostly during the Pleistocene epoch. The fans are characterized by weakly to moderately bedded deposits dominated by coarse clasts in a moderately to poorly sorted matrix, which varies from silty mud to coarse sand. Most of the alluvial sediments were deposited by high and catastrophic flood events. On the stable alluvial terraces and along the stable fault-scarps, Reg soils developed (Amit et al., 1994, 1995).

\subsection{The area of Evrona}

The Evrona playa is a $10 \mathrm{~km}$ long and $0.5-2 \mathrm{~km}$ wide morphological depression, crossed diagonally by the $>2 \mathrm{~km}$ wide Evrona fault zone (Garfunkel, 1981; Fig. 1b). This basin is one of several en-echelon tectonic basins bounded by subparallel left-stepping faults that are developed north of the Gulf of Elat (Ben-Avraham et al., 1979a, b; Ben-Avraham, 1985; Garfunkel, 1981; Freislander, 1994, 1995a, b; Bartov et al., 1998). These basins are filled with fluvial sediments and range in depth from several hundred meters to a few kilometers (Ben-Gai et al., 1993a, b; Freislander, 1994, 1995a, b). Shallow trenches that were excavated in the area of the playa expose several meters of alternating fluvial and playa deposits, mainly coarse sands, fine sands, silty sands, silts and silty clays (Amit et al., 1999). In the area of the Evrona basin, the Evrona fault zone consists of several fractures that create visible lineaments, most of which are quite sharp and straight. Many of the faults have a vertical slip plane and are straight, which is typical of strike-slip faults. According to Zak and Freund (1966), the Evrona fault has shifted alluvial fans at the eastern part of the southern Arava by about $600 \mathrm{~m}$ during the Late Pleistocene. Other evidence of this shift during 50000-70000 years ago have been found in coral reefs in the Gulf of Elat (Reches et al., 1987). Deep seismic reflection and SSR surveys across the Evrona shear zone reveal several flower structures typical of strike-slip faults (Ben-Gai et al., 1993a, b; Freislander, 1995a; Shtivelman et al., 1995).

\subsection{Paleoseismicity of Evrona}

Paleoseismic analysis of sediments in the Evrona playa reveals that at least six events $(M>6)$ have affected the area in the last 14000 years (Amit et al., 1999). The recurrence interval of large earthquakes $(M>6)$ during the Pleistocene to Holocene is estimated to be in the range of 1200-2000 years (Gerson at al., 1993; Amit et al., 1996; Porat et al., 1996, Enzel et al., 1994, 1996). Fault scarp degradation modeling and luminescence dating of faulted Holocene alluvial fan surfaces on the western margins of the Evrona playa, indicate that at least one large earthquake $(M>6.5)$ has occurred during the last 2000 years (Enzel et al., 1996; Zilberman et al., 1996). Amit et al. (1999) show that the most recent tectonic event occurred in the last 1000 years, displacing the surface by at least $1 \mathrm{~m}$, which implies an $\mathrm{M}>6.5$ earthquake magnitude. 


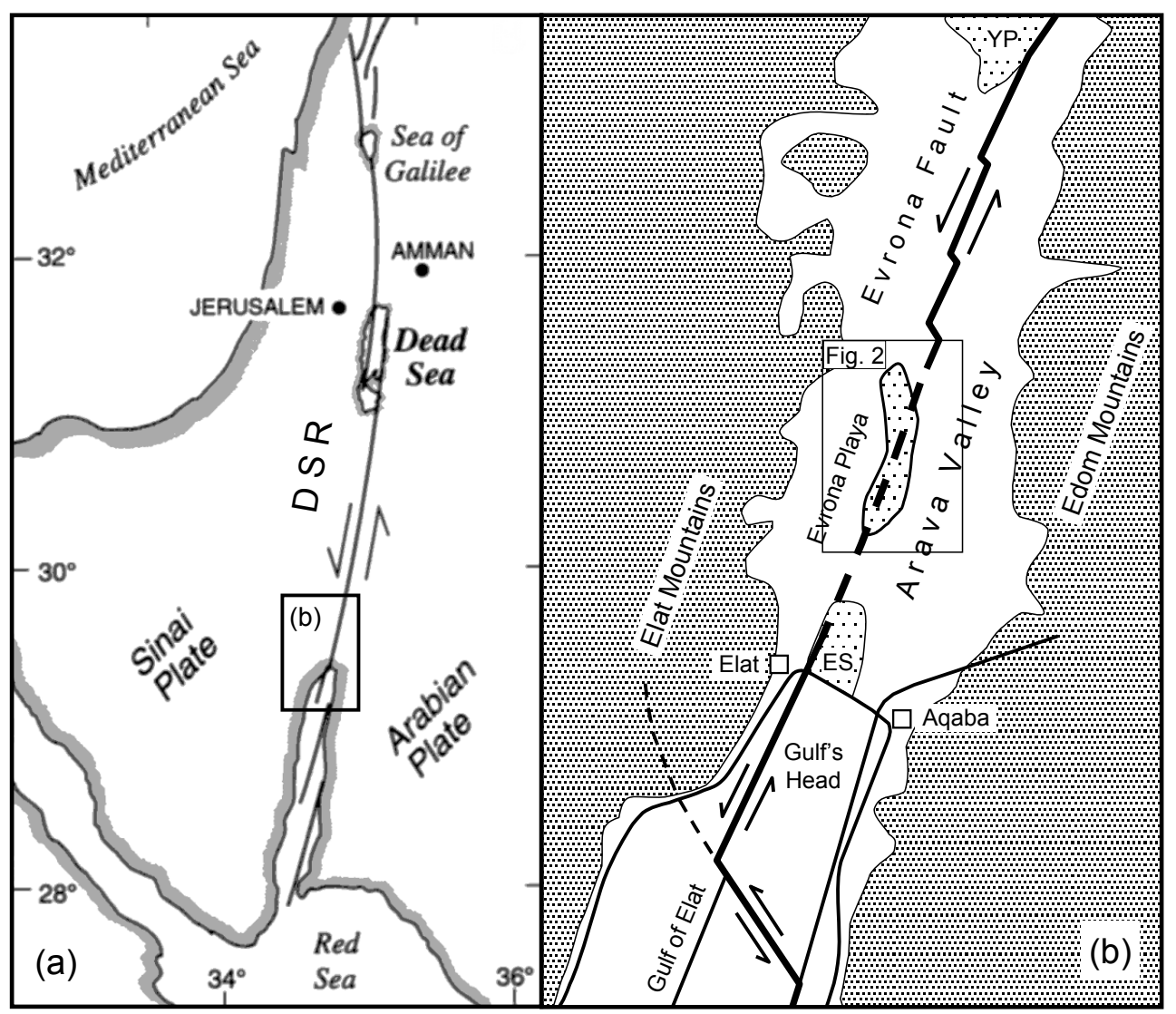

Fig. 1. (a) The Dead Sea Rift, a transform boundary between the Arabian plate and the Sinai plate (Map after Bartov, 1990). (b) Schematic illustration of the main faults of head of the Gulf of Elat and the southern Arava valley (based on data presented by Ben-Avraham, 1985; Reches et al., 1987; Ben-Avraham and Tibor, 1993; Shamir, 1996). The location of Fig. 2 is shown by a frame (YP = Yotvata playa, ES = Elat sabkha).

\section{Methods}

The Ground Penetrating Radar (GPR) was the main method that has been extensively utilized in this study. Using electromagnetic waves, GPR offers a unique high-resolution imaging of subsurface soil and rock conditions, from the near surface to a depth of several tens of meters (Basson, 2000). Approximately $17 \mathrm{~km}$ of GPR reflection profiles were obtained across the Evrona basin and its surroundings using the RAMAC GPR system. Several of the GPR profiles were obtained along the lines where Shallow Seismic Reflection (SSR) profiles were previously obtained by Shtivelman et al. (1998). Figure 2 shows the general locations of the GPR and the SSR profiles superposed on the geological map of the southern Arava valley and Elat area.

Most of the GPR reflection profiles were conducted using $100 \mathrm{MHz}$ center frequency at normal antenna configuration and transmitter-receiver offset of $1 \mathrm{~m}$. The measurements were taken at uniform intervals of $0.25 \mathrm{~m}$ between stations, while the antennas were lifted about $5-10 \mathrm{~cm}$ above surface and moved at an average slow walking speed of about $0.5 \mathrm{~m} / \mathrm{s}$ using a distance calibrated survey wheel. The GPR pulses were sampled at a sampling frequency of $1350-1700 \mathrm{MHz}$ and stacked 16-32 times. The duration of the $100 \mathrm{MHz}$ mea- surement at each station is about $0.25 \mathrm{~s}$, resulting in each station a linear dimension of about $0.125 \mathrm{~m}$. For practical purposes, therefore, the stations can be treated as point stations. In addition to the GPR reflection profiles, several GPR CMP (Common Mid Point) measurements that were conducted to measure the EM wave propagation velocity inside the deposits, provided an average value of $0.1 \mathrm{~m} / \mathrm{ns}$. Using the above settings and values, most of the GPR reflection profiles were conducted to map the top $25 \mathrm{~m}$ of the subsurface section of the Evrona Playa, and processed to enhance the discontinuities in its alluvial materials (Basson, 2000).

The SSR P-waves and S-waves profiles were shot by Shtivelman et al. (1998) using a sledgehammer source utilizing the conventional CMP technique with a shot and receiver spacing of $2.5 \mathrm{~m}$. Rough estimates of the depth range of the reflected events were made on the basis of RMS velocities derived from the seismic data. On the P-wave lines, these velocities vary from 800 to $2100 \mathrm{~m} / \mathrm{s}$ (uppermost and deepest parts); on the S-wave line, the velocities range from $350 \mathrm{~m} / \mathrm{s}$ to $500 \mathrm{~m} / \mathrm{s}$. According to these velocities, the shallowest clear P-wave reflectors appear at a time of about $40 \mathrm{~ms}$, which is $\approx 20 \mathrm{~m}$ deep, while the deepest reflector that can be reliably detected, up to a time of $150 \mathrm{~ms}$, is $\approx 150 \mathrm{~m}$ deep. The shallowest reflectors of the $\mathrm{S}$-wave, which appear more 


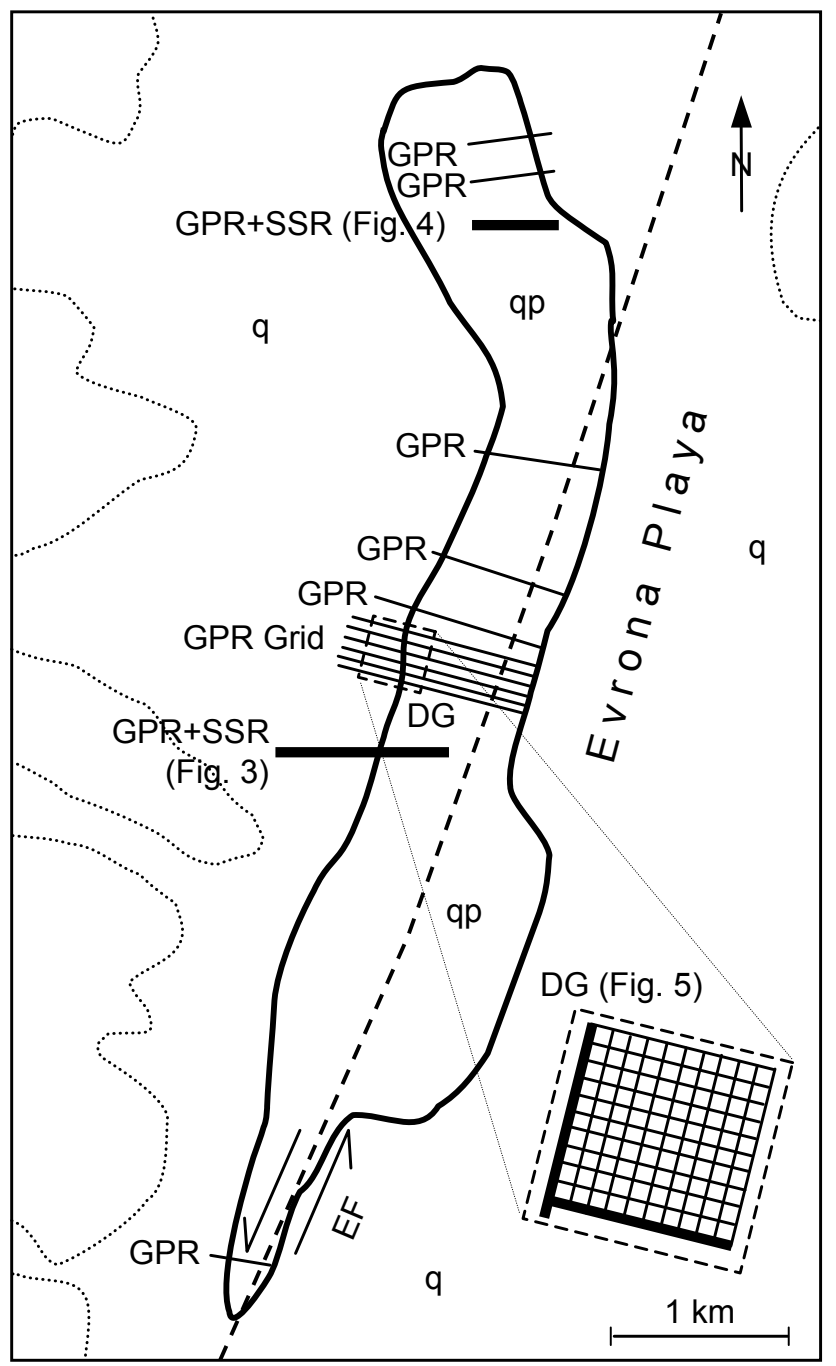

Fig. 2. Schematic illustration of the study area of Evrona playa superposed on the main faults and topographic features. The light dashed line mark undifferentiatted conglomerates; q: Neogene Quaternary units, Quaternary alluvium (gravel, sand, silt); and qp: Quaternary playa deposits (clay, silt, sand); EF: Evrona Fault. The GPR and SSR profiles presented in this paper (in the northern and the center parts of Evrona) and locations of Figs. 3-5 are marked with thick lines. The enlargement of the dashed frame on the GPR grid mark a dense grid: DG.

clearly on this profile than on the overlapping P-wave profile, are detected at a time of about $10 \mathrm{~ms}$, at a depth of $\approx 17.5 \mathrm{~m}$. The deepest part of the $S$-wave profile is at $\approx 200 \mathrm{~m}$. It should be noted that the uppermost returns of the SSR profiles may be interference images of refractions and reflections. Therefore these returns should not be treated as pure reflections (Shtivelman et al., 1998).

Spatial resolution (or horizontal resolution) refers to the ability to detect lateral changes along a reflector, such as those caused by faults or facies changes. Most of the reflected energy that arrives at the receiver does not come from a single point of incidence, but from a circular zone on the reflector known as the first Fresnel zone, which diameter is $(2 Z \lambda)^{1 / 2}(Z$ is the depth of the reflector and $\lambda$ is the dominant wavelength). For Evrona measurements, the shallowest P-wave reflections have been detected at a depth of about $20 \mathrm{~m}$, while the shallowest $\mathrm{S}$-wave reflections have been detected at a depth of about $10 \mathrm{~m}$. Since the dominant frequency values, $f$, were about $150 \mathrm{~Hz}$ and $50 \mathrm{~Hz}$ with velocities, $v$, of about $900 \mathrm{~m} / \mathrm{s}$ and $350 \mathrm{~m} / \mathrm{s}$ respectively, the computed wavelengths, $\lambda$, are about $6 \mathrm{~m}$ for the P-wave and $7 \mathrm{~m}$ for the $\mathrm{S}$-wave $(\lambda=v / f)$. Therefore, the approximate spatial resolution of the shallowest P-wave reflectors is $15.5 \mathrm{~m}$ and $12 \mathrm{~m}$ for the $\mathrm{S}$-wave. However, since the average GPR wavelength is about $1 \mathrm{~m}$, its spatial resolution is significantly higher - about $4.5 \mathrm{~m}$ at a depth of $10 \mathrm{~m}$. Using the $1 / 8$ wavelength criterion of Widess (1973), the maximal vertical resolution (the ability to distinguish between closest layered reflectors) is about $0.125 \mathrm{~m}$ for the GPR and about $0.8 \mathrm{~m}$ for the seismic waves. Since $0.25-0.5$ of a wavelength are more realistic, the average vertical resolusion varies from $0.25-0.5 \mathrm{~m}$ (GPR) to 1.5-3.5 m (SSR). These differences explain the superior resolution of the GPR data, and the better results of the S-wave profile compared to the P-wave profiles.

A numerical model of a faulting process based on the Continuum Damage Mechanics theory summarized by Lyakhovsky et al. (1997a, b) and references therein was applied to inspect the interpretation of the GPR and SSR observations. The model addresses the cumulative effect of distributed micro-cracks and flaws in the elastic material, the development of a process zone sourrounding a pre-exsisting fault, and simulates the propagation of a narrow fracture zone. We used a two dimensional numerical code (Weinberger et al., 1999) to compute the stress and damage fields within a rectangular area with grid points $100 \mathrm{~m}$ high and $50 \mathrm{~m}$ wide every $1 \mathrm{~m}$, assuming increasing plane strain conditions. In order to add the effect of a lateral strain that is typical to the Evrona fault zone, a constant lateral shear strain (perpendicular to the 2D grid section) is also applied. The boundary conditions of computer modeling are reduced to a local stress, which is applied at the bottom of the section to simulate pre-existing fault zone. The upper boundary, i.e. the surface, is kept free, while a vertical slip velocity $\mathrm{V}_{\text {slip }}$, equivalent to the one localized on the pre-existing fault zone, is applied at the bottom. The density, elastic moduli and internal friction are computed using parameters from the test of Lambe and Whitman (1969), and from Shtivelman et al. (1998).

\section{GPR and SSR profile images of the Evrona fault zone}

The GPR profiles show tens of subsurface discontinuities per kilometer at different depth ranges below the surface and with varying spacing intervals and clustering. Most of the discontinuities detected by the GPR profiles were interpreted as fractures or faults. Three main criteria (and their combination) were used for the interpretation: 

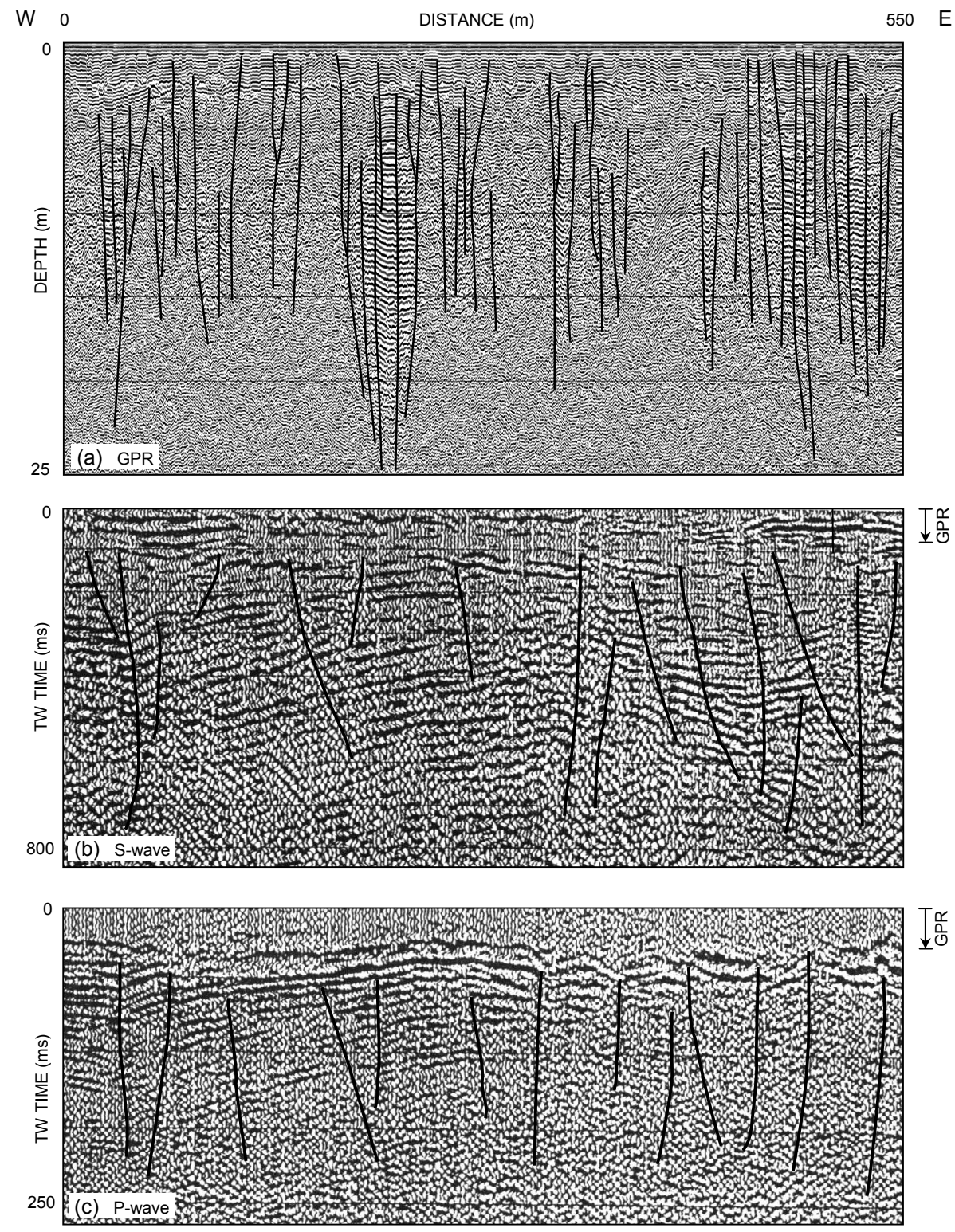

Fig. 3. $550 \mathrm{~m}$ of the GPR and SSR S-wave and P-wave profiles conducted in the same location - the center of Evrona area (see location in Fig. 2). (a) GPR profile conducted to a depth of about $25 \mathrm{~m}$ : The faults seem to cluster into groups. (b) S-wave and (c) P-wave SSR profiles (note the differences in two-way time scale): The undulated reflectors and the discontinuities interpreted as faults, some of which form flower structures. The shallow reflectors appear in this S-waves profile with better quality than in the P-wave profile. The depth of penetration of the GPR profile (a) is shown at the seismic profiles by arrows.

1) minor discontinuities of reflectors (minor offsets or thickness variations), which indicate fractures;

2) abrupt unconformities and sudden variation of lateral reflectors, which is indicative of a strike slip component;

3) vertical displacements of reflectors, which indicate either normal or reverse faults with dominant dip-slip motion and with sub-horizontal bedding.

The high number of fractures and faults may indicate a vigorous neotectonic activity in the area of Evrona.
Figure 3 shows a $550 \mathrm{~m}$ long section of GPR, SSR S-wave and P-wave profiles conducted in the center of the Evrona area (see location in Fig. 2). The profiles were conducted at the same location. The GPR profile (Fig. 3a) shows a variety of discontinuities within the alluvial layers. About 50 faults are detected in this profile and seem to cluster into several groups. The S-wave profile (Fig. 3b) shows a sequence of reflectors that can be traced along the profile down to $700 \mathrm{~ms}$ (about $175 \mathrm{~m}$ depth). The continuity of the relectors is interrupted at many locations along the entire section. These discontinuities may be interpreted as shallow faults with minor vertical displacements, which form, at depth, flower struc- 


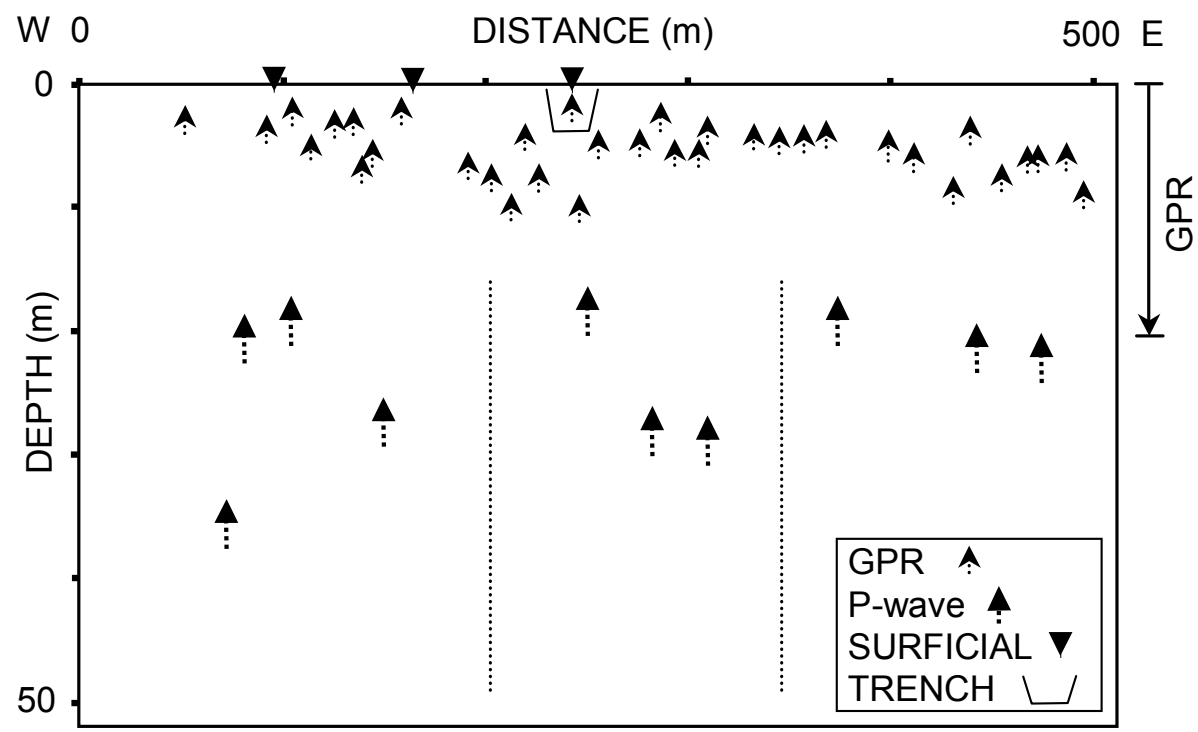

Fig. 4. A compilation of the location of two surficial tectonic lineaments and fault a scarp that crosses the GPR and the SSR P-wave profiles in the northern part of Evrona (The GPR and the P-wave profiles were processed similar to the profiles presented in Fig. 3). The triangles represent the tectonic surficial features (see Amit et al., 1999, for the excavation of trench T-20 in the area of the scarp). The small arrows represent the GPR results and the large arrows represent P-wave results. The depth of penetration of the GPR profile is shown at the right side of the figure by an arrow. Note the division into a three different groups.

tures typical of strike-slip faults. Some of the faults can be traced to a depth of about $17.5-20 \mathrm{~m}$. The same sequence of reflectors and disturbance areas can be detected by the Pwave profile (Fig. 3c). However, the S-wave section provides a more detailed picture of the shallow subsurface, apparently because the signal/noise ratio is higher and the spatial resolution is better.

Similar results were obtained in the north of the Evrona playa (see location in Fig. 2). Figure 4 highlights the differences between surficial expressions, GPR imaging, and SSR $\mathrm{P}$-wave imaging. The triangles at the surface represent topographic expressions of two tectonic lineaments and a fault scarp (the fault scarp of Ein Evrona excavated (T-20) by Amit et al, 1999). This compilation of results emphasizes the significant differences between the surficial topographic expression, which was influenced only by 3 recent faults, and the SSR results that show 10 faults. Some of the faults detected in the SSR profile probably reaching closer to the surface cannot be traced at shallow depth range. The GPR results show about 35 faults (and more, as will be shown below) in the top $10 \mathrm{~m}$, some of which are probably the continuation and splits or splays of the faults that were detected in the SSR profile. Since only 3 faults influence the surface topography to a degree that is apparent to the naked eye, it is clear that the GPR results express the recent tectonic activity of that area better than the other methods.

\subsection{Grid of GPR profiles}

The high density of shallow faults detected by GPR contrasts with the low number of fractures counted at the surface was surprising. In order to investigate this observation and to cre- ate a higher level of detail, a grid of GPR profiles was obtained across the center of the Evrona playa (Fig. 2). A strip of 6 close parallel profiles was conducted (each profile of about $1150 \mathrm{~m}$ long, intervals of $50 \mathrm{~m}$ ) nearly perpendicular to the south-southwest north-northeast trend of the Evrona fault zone, across the playa through several fault scarps and tectonic lineaments. The western side of the strip was of special interest: The "tectonic" reason was to trace the continuation of a prominent horst structure, located in the northern area, seen at the surface as a curved multiple fault scarp. This structure seems to vanish southward. The second reason is that this area is the most suitable for creating several high quality GPR profiles that are almost unaffected by topographic changes and surficial obstacles. Therefore, a set of 11 south-north profiles and 5 west-east profiles were added in this area to form a dense square grid, composed of 11 profiles by 11 profiles of about $250-300 \mathrm{~m}$ long each, at intervals of $25 \mathrm{~m}$ (see location in Fig. 2, the western part of the grid).

Two profiles, located at the western and the southern edges of the dense GPR network, in an area that appears to be flat and undisturbed on the surface, are shown in Fig. 5 (the two thick perpendicular lines shown in Fig. 2). These profiles are plotted at a detailed scale. The horizontal scale is more than twice larger than the horizontal scale of the GPR profile shown in Fig. 3a. This large horizontal scale together with a vertical exaggeration of about $400 \%$ were found to be the optimal setting for the Evrona fault zone, showing a high level of discontinuity. It enhances the ability to distinguish short reflectors with horizontal dimension of about $1 \mathrm{~m}$, so that the maximal number of fractures and faults in the profile stand out clearly. 

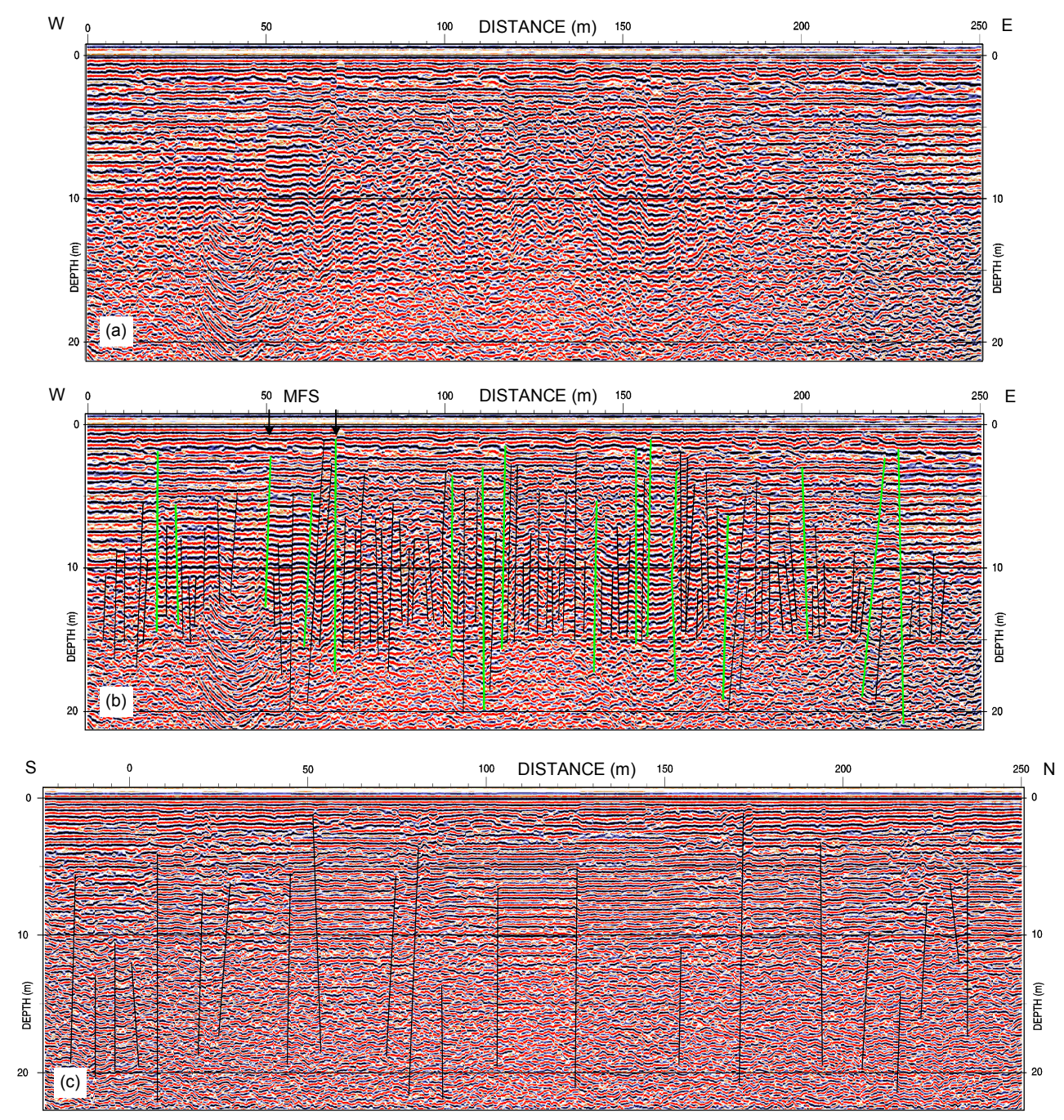

Fig. 5. A very detailed original (a) and interpreted (b) west-east profile (see location in Fig. 2, the thick western line of the dense grid: DG). This detailed scale of the $250 \mathrm{~m}$ length profile enhances the ability to distinguish short reflectors (the horizontal scale is more than twice larger than the horizontal scale the GPR profile shown in Fig. 3a). The interpretation is shown in (b), where the main faults are marked with green. The continuation of the multiple fault scarp (MFS) is marked on the profile. (c) A very detailed interpreted $270 \mathrm{~m}$ of a south-north profile, the western profile of the GPR grid (see location in Fig. 2, the thick southern line of the dense grid: DG). The detailed scale enhances the ability to distinguish short reflectors and faults. Note the smaller number of faults in this south-north profile relative to the west-east profile.

Figures $5 \mathrm{a}$ and $5 \mathrm{~b}$ show the original and the interpreted west-east GPR profile. About 90 discontinuities that can be interpreted as fractures and faults are marked on the profile presented in Fig. 5b. The processing and the resolution of this profile allows detecting and tracing of most of the faults generally to a depth of about $15 \mathrm{~m}$, and some faults to a depth of $20 \mathrm{~m}$. The main faults that are marked with green color can be seen relatively clear at coarser scale such as in Fig. 3a.

The south-north profiles of this area also appear intensely faulted, although their degree of faulting is less than in the west-east profiles. Figure $5 \mathrm{c}$ presents the western profile of the grid at a very detailed scale. About 22 faults are detected along this profile, far less than the number of faults present at a typical west-east profile. This observation is probably related to the fact that the general trend of the Evrona fault is almost parallel to the south-north profiles, and nearly perpendicular to the west-east profiles.

The total number of faults increases as a function of depth. A counting parameter - termed the "number of residual faults" at a given depth range - may be defined as "the number of faults that reach a given depth level but not the one immediately above it". The number of residual faults between two horizontal levels is therefore calculated by subtracting the total number of faults that reach the roof of a given depth level from the total number of faults counted at its bottom. Figure 6 shows the results of this fault distribution analysis for three representative GPR profiles of the array. The graphs in Fig. 6a show an increase in number of faults as a function 


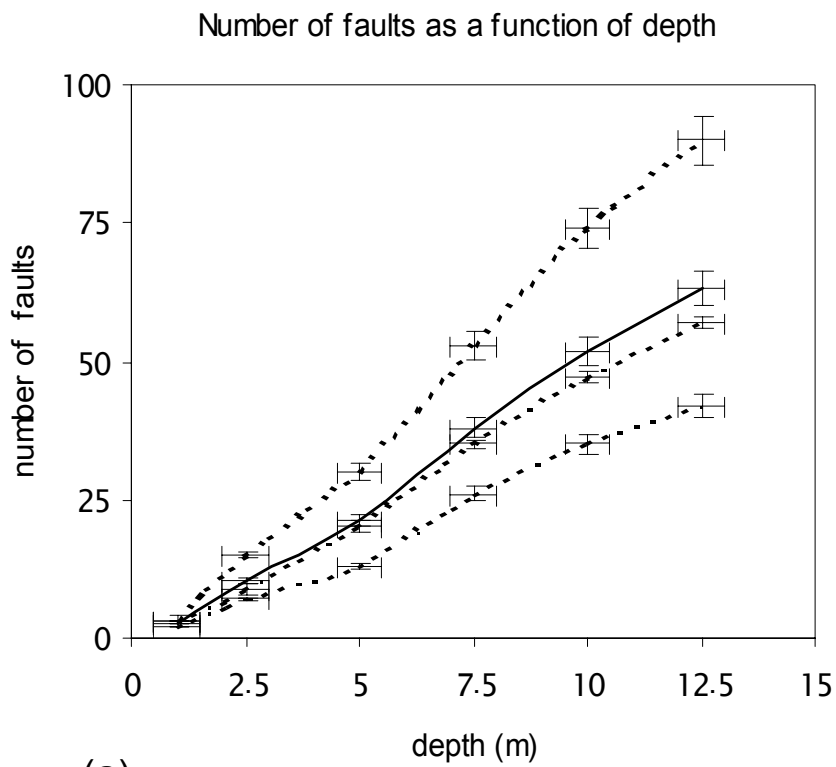

(a)
Number of residual faults as a function of depth range

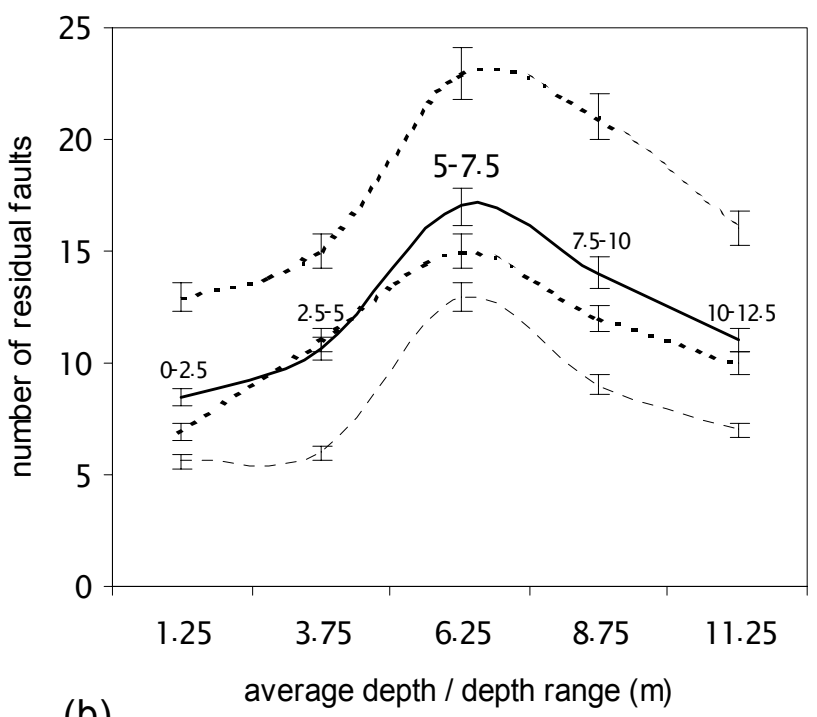

(b)

Fig. 6. (a) Graph of the analysis of the total number of GPR discontinuities, which are interpreted as faults, as a function of depth for 3 representative west-east profiles (dashed curves) from the southern the area of the dense grid of GPR profiles (see location at Fig. 2). The depths are $12.5 \mathrm{~m}, 10 \mathrm{~m}, 7.5 \mathrm{~m}, 5 \mathrm{~m}, 2.5 \mathrm{~m}$ and $1.25 \mathrm{~m}$. The total number of faults (or the "cumulative number of faults") at a certain depth was counted from each one of the interpreted profiles. The average curve (thick line) represents the typical total number of faults as a function of depth for the area of the dense GPR grid as it appears in the west-east profiles. (b) Graph of the analysis of the number of "residual" GPR faults as a function of depth range for the same setting presented in Fig. 6a. The peak number of faults appear at the depth range of 5-7.5 m (the depths in the graph were set to the center value, i.e. to the average depth between the bottom and the roof of each depth range).

of depth for the three west-east profiles (one of which is presented in Fig. 5b). The accuracy of the observation, shown by the crossbars on each data point, is about $\pm 0.75 \mathrm{~m}$ for depth and about $\pm 5 \%$ for the number of faults. This accuracy minimizes the subjectivity inherent to the interpretation, since it gives a sufficient degree of freedom in determining the depth reached by the faults as well as their number. A linear regression of the average curve shown in Fig. 6a yields a correlation parameter $\mathrm{R}^{2}=0.99$ with the linear approximation $\mathrm{N}_{f}=5.4 \mathrm{D}-3.4$, where $\mathrm{N}_{f}$ is the number of faults and $\mathrm{D}$ is the depth. According to this approximation, for example, the average number of faults that can be found at a depth of $1 \mathrm{~m}$ along the azimuth of $100^{\circ}$ is 2 .

The number of residual faults as a function of depth range (or average depth) for the three representative GPR images is presented in Fig. $6 \mathrm{~b}$. The curves show a peak in the number of residual faults that penetrate the depth range between 5 to $7.5 \mathrm{~m}$ below the surface. Based on the curve representing the average profile, an average of about 17 "new" faults are detected in this depth range. This peak value is about $20 \%$ higher than for the depth range below $(7.5-10 \mathrm{~m})$, and about $55 \%$ more than for the depth range above $(2.5-5 \mathrm{~m})$. (Note: The GPR measurements of Evrona were not set to measure shallower than a depth of about $1 \mathrm{~m}$. Therefore, in order to compare equal intervals of $2.5 \mathrm{~m}$, the data for the range of 0 $2.5 \mathrm{~m}$ presented in this graph were extrapolated and weighted from the measured range of $1-2.5 \mathrm{~m}$ ).

\section{Mechanical implications of shallow faulting in the Evrona fault zone}

The GPR observations described above, of the top several tens of meters of the alluvial sediments of the Evrona playa and the southern Arava valley show that the number of faults increases as a function of depth, at least in the uppermost 15 to $25 \mathrm{~m}$. Moreover, the apparent dips of the faults suggest that many of the discontinuities merge at a depth of a few tens of meters.

These observations are consistent with seismic reflection observations, which generally identify a parent fault below a group of faults that are detected by GPR. According to both seismic and radar observations, a typical single active fault, traced through the top hundred meters of the alluvial sediments changes its mechanical characteristics abruptly as it reaches a depth range of about $35-20 \mathrm{~m}$ below the surface. It then proceeds towards the surface in a series of splays. As a result of this mechanism, the tectonic displacement that accumulates along a plane of a parent fault is dispersed towards the surface.

\subsection{Linear shear strength decrease (LSSD) model}

According to the "Mohr-Coulomb law of failure", the strength of a rock (capacity to resist faulting) is a function of its cohesive strength and of its internal friction resistance to faulting. Therefore, the stress required to fracture a rock 

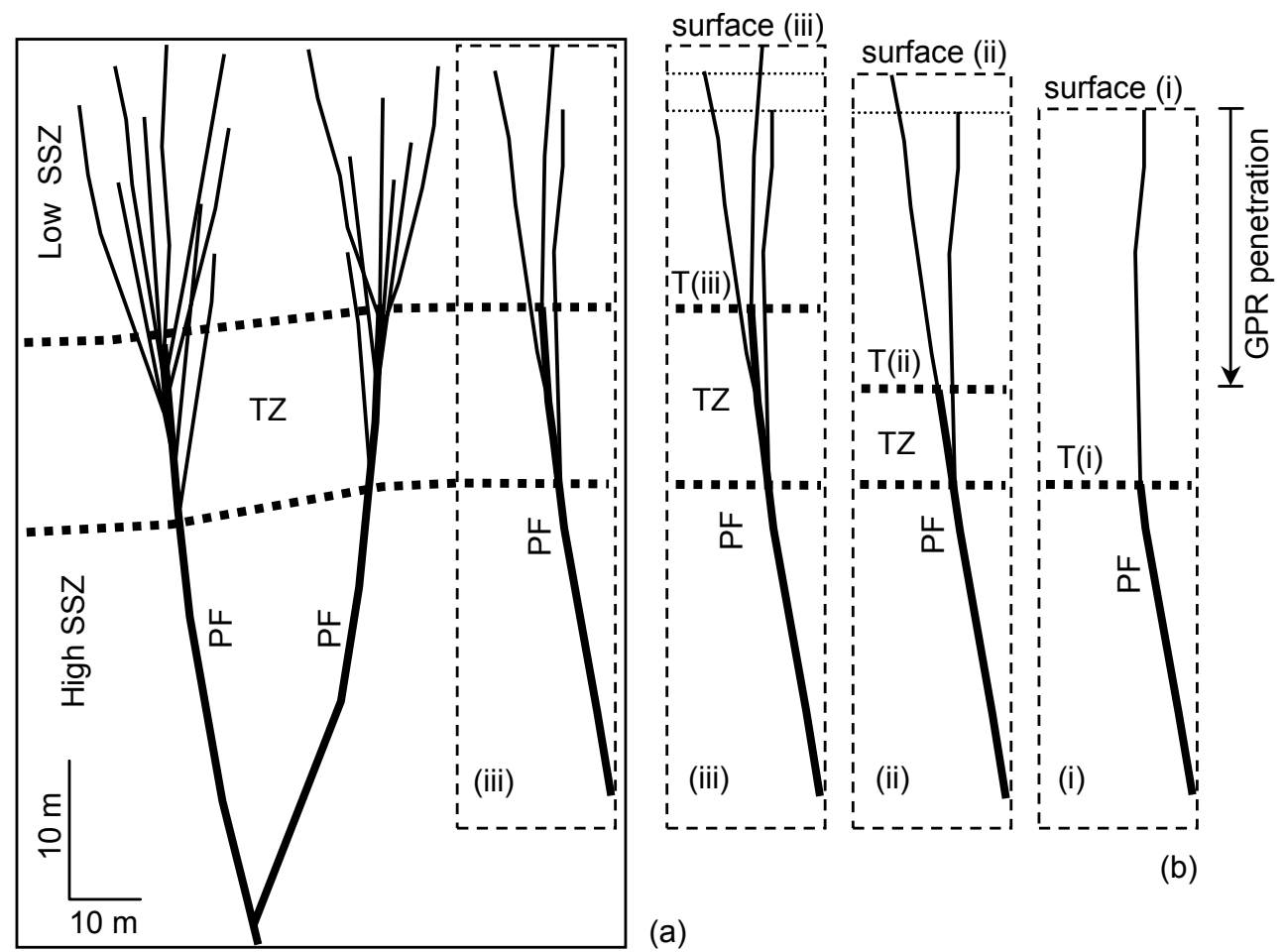

Fig. 7. (a) Three distinct zones of shear strength that control the mechanical behavior of faulting in unconsolidated alluvial materials at various depths: a high shear strength zone (High SSZ), a transition zone (TZ) and a low shear strength zone (Low SSZ). A "high" shear strength zone refers to the deeper subsurface interval in which the mechanical conditions cause reactivation of a fault along a pre-existing plane of the parent fault (PF). A "low" shear strength zone refers to the uppermost surface interval, in which the mechanical conditions do not constrain the fault to reactivate along the pre-existing plane; therefore, the fault continues to propagate towards the surface randomly and splays. According to this scheme, the closer the faults are to the surface the younger they are. In addition, the youngest faults show a shallower level of splaying. Consequently, the level at which older faults splayed is deeper. (b) Migration stages of the transition line (T) and the splay point of the PF in the "frame a" towards the new surface as the load on the surface grows. Stage "(i)" is an initial stage, showing a parent fault propagating towards the surface through the T(i). In stage "(ii)", alluvial materials have accumulated on the surface, causing migration of the old transition line T(i) to a new level T(ii) located at the same depth relative to the new surface. The parent fault propagates to the new surface along a different random plane and the first "splay" is abandoned as presented in stage (iii). An average depth of penetration of the GPR profiles is shown at the right side of the Figure by an arrow.

must be large enough to overcome the cohesive strength; at the same time, it must be large enough to overcome the rock's interior resistance to faulting, so that the movement can take place along the fracture.

The fault distribution within the uppermost $100 \mathrm{~m}$ of the surface in the Evrona fault zone, as seen by combining GPR and SSR observations, can be explained by a Linear Shear Strength Decrease (LSSD) Model that is developed in this study. The LSSD model suggests the presence of three distinct zones of shear strength that control the mechanical behavior of faulting in the unconsolidated alluvial materials near the surface: a high-shear strength zone, a transition zone and a low-shear strength zone (Fig. 7a). A "high" shear strength zone refers to the deeper subsurface interval in which the mechanical conditions cause for a propagation of a fault along a pre-existing plane. A "low" shear strength zone refers to the uppermost section, in which the mechanical conditions do not constrain the fault to propagate along the pre-existing plane; therefore, the fault continues towards the surface randomly.
The zonation of shear strength results from changes in depth in the lithostatic pressure and the hydraulic pressure, which contribute to the cohesion of the unconsolidated alluvial sediments (the resistance due to internal friction is negligible). The static pressure is a function of the average total density, the acceleration due to Earth's gravity and the depth. The average total density of the alluvial sediments can be considered constant, because no characteristic changes are detected at the border between the "high" and "low" shear strength zones in the GPR and the SSR profiles. Therefore, in this approximation, depth is the only parameter influencing the static pressure, and thus the cohesion and the shear strength.

The LSSD model suggests that shear strength decreases linearly with decreasing depth towards the surface. This observation is similar to the behavior of marine clay as reported by Lambe and Whitman (1969), which show that while the shear strength of the material decreases linearly from a depth of about $24 \mathrm{~m}$ towards the surface, the plastic limit of this soft homogeneous marine clay is reached sharply around about 

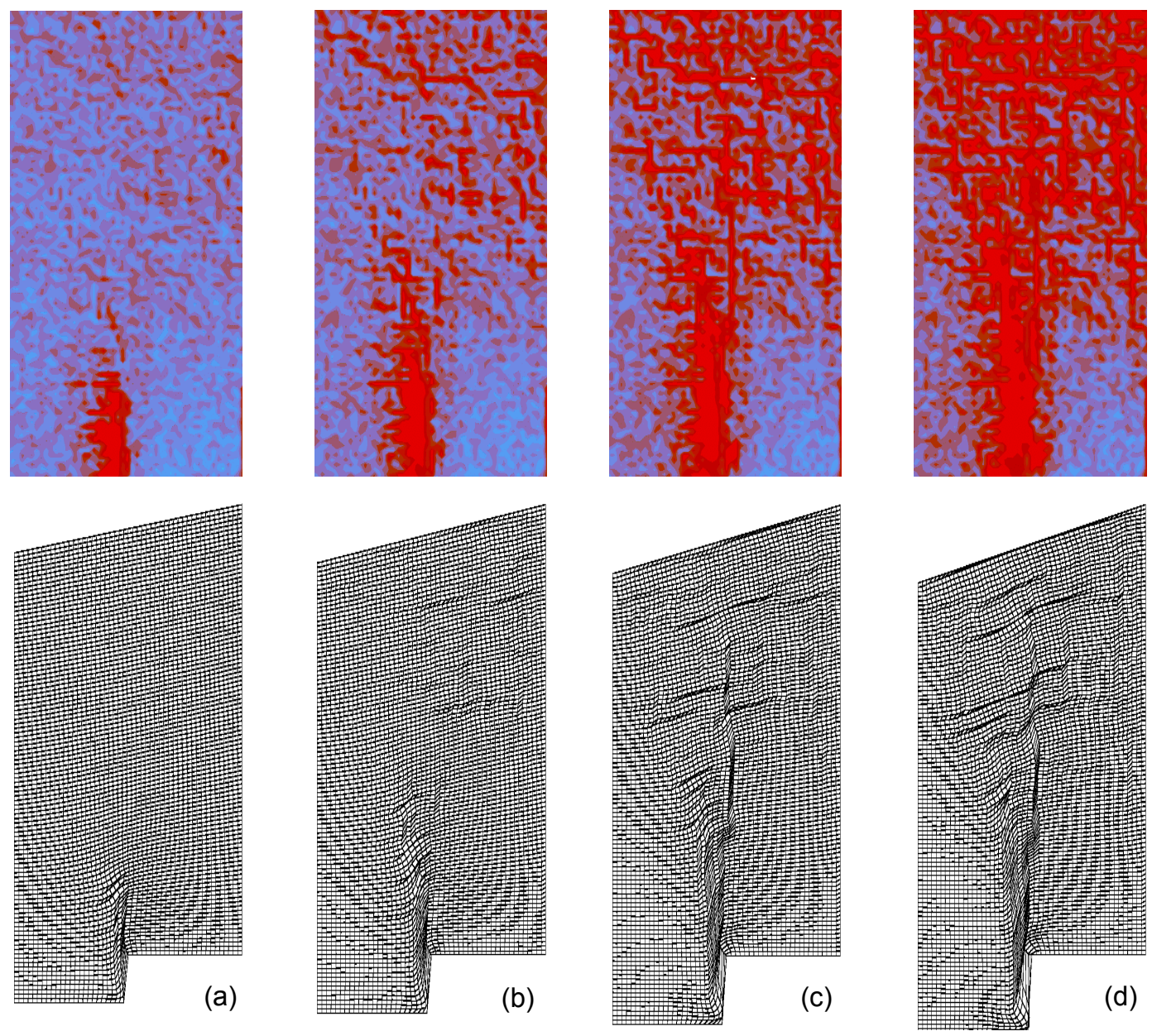

Fig. 8. Damage Modeling and Fault Propagation Modeling in four stages. The grid size of each stage is $50 \mathrm{~m}$ wide by $100 \mathrm{~m}$ deep. Damage Modeling (the upper part of the Figure) - evolution of fault damage as a function of the fault's propagation time. The red colors represent the propagating fault and the micro-cracks that develop; the blue colors represent undamaged material. Stage (a) shows the fault (the red area at the bottom) after a minor upward movement towards the surface. The red stains are micro-cracks, which have developed as a result of random flaws inside the material. Stage (d) shows an advanced stage of damage, suggesting a possible mechanism for branching of faults as they near the surface. Fault Propagation Modeling (the lower part of the figure) - growth of the fault as a function of time. Stage (a) shows an initial stage of upward propagation of the fault towards the surface. Stage (d) shows the developed stage of the fault, as it approaches the surface.

$15 \mathrm{~m}$ below the surface. By analogy, the combination of the fine alluvial materials that compose the sediments of Evrona as well as the presence of a shallow water table at a depth range of about 15-20 m (Gev, 1999) may cause a plastic behavior.

According to the LSSD model, the shear strength of the alluvial sediments of Evrona decreases linearly as the depth decreases at a rate such that a transition zone is reached at a depth range of $20 \mathrm{~m}$ to $35 \mathrm{~m}$. At greater depths (below the transition zone), parent faults propagate through the high shear strength zone; assuming that the healing time is fast enough, energy balancing dictates that they react along a preexisting plane. If the released energy along the fault is strong enough to allow its continuation to the surface, its path above the transition zone through the low shear strength zone will be affected only by the local conditions that allow minimal energy loss. The path of the fault in the uppermost low shear strength zone interval between the depth of the transition zone and the free surface will be then randomly distributed, leading it to splay as the tectonic activity progresses.

The reason that the faults do not coalesce at specific, welldefined depths seems to be related to the fact that failure takes place at varying times and under changing loading conditions. The fault therefore splays at various depths, defining a transition zone rather than a plane that marks a single plastic limit at a specific depth. Figure $7 \mathrm{~b}$ illustrates the migration of the splay towards the new surface as the load grows. If the load increases linearly, the parent fault and the splays propagate towards the surface.

Local mechanical conditions can also exist due to minor lithological variations which are too thin to be detected by GPR. A delicate change within a thick layer may be unperceivable in the image, yet may be mechanically significant. For example, thin, non-uniform layers of solid gypsum, 
with thicknesses of only several centimeters, are typical in the Evrona basin. Such nonuniformity may cause low shear strength to be localized, having the effect of tunneling a fault toward the surface through zones of local weaknesses.

The LSSD model explains the splaying of a parent fault towards the surface through unconsolidated materials. The model does not consider the local compaction effect of the conjugate strain that accompanies an abrupt propagation of a fault towards the surface. This effect can cause variable compaction in zones above the fault, resulting in enlargement of weak zones that tunnel the propagation of the fault. Compaction may also have varying influence on a series of distinct layers of alluvial materials, enhancing the differences between them and hence their visibility on the GPR image. The effect of compaction is dealt in the fault growth modeling described below.

\subsection{Modeling of damage evolution and fault propagation}

The results of computer simulations demonstrating a possible mechanism of faulting within the top $100 \mathrm{~m}$ of the Evrona fault zone are shown in Fig. 8. The series of four figures (a to d) represent increasing degrees of damage due to the progress of the fault from the bottom. The red color represents the fault and the micro-cracks. It can be seen that damage is diffused towards the surface, creating a "cloud" of micro-cracks, suggesting that the fault, which is confined at depth, can penetrate the surface in several random locations. Figure 8d represents the highest level of damage and most extensive branching of the main fault toward the surface.

Four stages of the fault growth modeling are presented by grid deformation in the lower part of Fig. 8, from initial propagation (8a) to near breaking of the surface (8d). Two clear effects are seen as the fault grows: the main effect is the extension of the fault towards the surface and its tendency to branch out, or to "erupt"; the second is the formation of "compact layers" perpendicular to the main propagation plane (the deformation is exaggerated 10 times, in order to emphasize the effects). These two effects are the result of conjugate strain; the main one causes failure of the material, while at the same time the other compresses the material perpendicularly, due to a minimal internal friction resistance to faulting. The advantage of the fault growth modeling, relative to the other models presented, is the ability to show the simultaneous effects: "layering" and "splay".

\subsection{Synthetic radargram of density-layering effect}

An interesting result of the fault growth modeling is the compaction effect that occurs as a fault propagates. The compaction effect changes the initial homogeneous material into nearly flat layers of different densities. This phenomenon, of layering due to compaction, which can be seen best in Fig. 8d, was logged and scaled in order to be remodeled as a synthetic radargram to show how such layering would be seen in a radar section. Since a reflection coefficient of an EM wave is a function of the dielectric constants of the two
DIELECTRIC MODEL

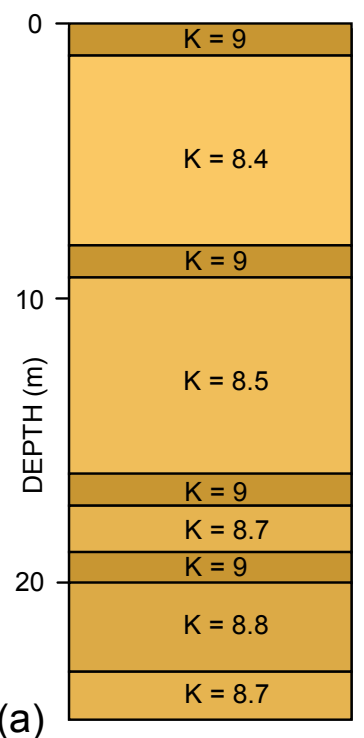

(a)

Fig. 9. Synthetic radargram of the Density-Layering effect. The dielectric model of the layers (a) is shown next to the derived radargram (b), to a depth of about $25 \mathrm{~m}$. Reflections occur due to dielectric variations among the layers (multiple reflections are marked with "M").

layers surrounding the interface zone, the density of the layers have been transformed into dielectric constants to create the radargram.

The synthetic radargram modeling used here assumes a subsurface flat-layered environment on which a plane wave incidents vertically. The earth model is transformed into a time thickness series that is excited with a time-stepping impulse. All the reflections, including the multiples and interlayer reflections, are computed and the impulse response of the layered model is generated. Then, a convolution of the impulse response model with the radar wavelet is applied to emulate the radargram.

In the uppermost $25 \mathrm{~m}$, the typical GPR penetration, the model consists of four dense layers detached by layers of lower density. As computed from the fault growth modeling (the top $25 \mathrm{~m}$ of stage d), the density of most of the dense layers is about $7 \%$ higher than the initial density of the homogeneous material. Since the effective dielectric constant of a layer is a function of the mixing ratio of its bulk components, a change in a density of a layer, i.e. a change of the mixing ratio of quarts grains, air and moisture dominates a change in the effective dielectric constant. Accordingly, since the measured average dielectric constant of alluvial material in Evrona is about 9, and the transformed density to dielectric constant changes are up to about 0.6 , the dielectric constant values of the modeling range between 8.4 and 9. Figure 9a shows a model consisting of different density layers transformed into layers of different dielectric constant. The results of the derived synthetic radargram (Fig. 9b) show that minor changes in the dielectric constants are enough to generate clear reflections. The synthetic radargram and the fault 

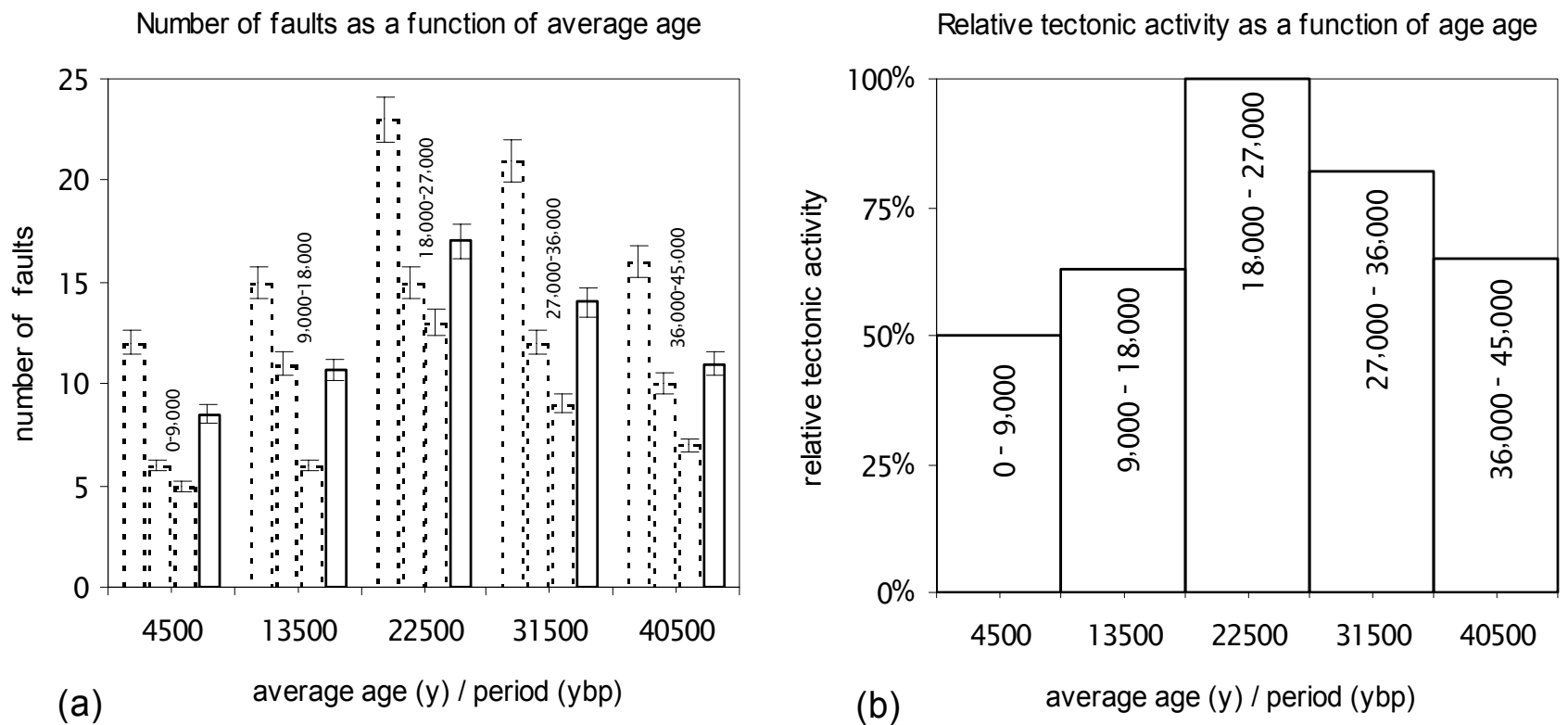

Fig. 10. (a) Analysis of the number of faults as a function of average age / period (ybp) for the three representative GPR profiles (dashed colomns) at the grid of GPR profiles (modified from Fig. 6b). The average colomns (thick lines) represents the typical number of faults as a function of average age / period (ybp) for approximately the last 45000 years. Note a peak in number of faults at the age of $22500 \mathrm{ybp}$ $( \pm 1200)$, and the continuous decrease towards present time. (b) The level of tectonic activity during the last $45000 \mathrm{y}$ relative to the peak wave of tectonic activity detected at the period of 18000-27000 ybp. The peak wave level is about $37 \%$ higher than the average tectonic activity computed for the entire period. The level of tectonic activity of the recent period, during 0-9000 ybp, is the minimal measured, about $70 \%$ of the average level of tectonic activity for the entire period, and about $50 \%$ of the peak period.

growth modeling supports and strengthen the interpretation of the coherent reflectors appear in the GPR profiles (e.g. Fig. 3a.) as a result of the physical phenomenon of "layering effect", diminishing the possibility that they are only multiple ringing.

\section{0 years of tectonic activity in the Evrona fault zone}

Analysis of the faults detected by the GPR in Evrona can help in evaluating the relative level of tectonic activity of the active fault zone. Based on age dating of samples taken from several trenches in the Evrona area (exposing about $4-5 \mathrm{~m}$ below the surface), the average sedimentation rate is about 3,600 y/m $( \pm 1200)$ (Amit et al., 1999 and references therein). Assuming the sedimentation rate has not varied significantly in the last several tens of thousands years, the age of the sediments at a depth of $12.5 \mathrm{~m}$ is about 45000 years.

\subsection{A Wave of tectonic activity at the Evrona playa}

The profiles conducted in the dense GPR network of Evrona playa reveal, as described above, a surprisingly large number of faults per unit of length in the top $15 \mathrm{~m}$ of the subsurface volume. Moreover, it was found that the total number of faults increases as a function of depth. Since most of the faults have vertical displacements of several tens of centimeters and they are observed at shallow depths, this suggests that they are a result of strong tectonic events (i.e. $M>6$ ), so that they could penetrate to the surface at the time of the tectonic activity (Bonilla et al., 1984). According to the models described above, the propagtion directions of the faults are not constrained by the reactivation of an existing fault (i.e. they splay rather than continue to propagate along a single plane), therefore the number of faults as a function of depth may be an indication of the level of the tectonic activity at the time they were active.

Since the GPR observations show the same pattern of faulting for the different depths (Fig. 6a), it is assumed that the faulting behaviour does not vary as a function of depth. Accordingly, at each depth the ratio of faults that reach the surface should be similar. Therfore, even though not every single fault reaches the surface, the number of faults as a function of depth is still indicative of the relative level of the tectonic activity.

Whether all the faults or just a portion of them reached the surface, it is interesting to note their distribution with depth. The faults of the dense GPR grid can be separated into different groups according to their relation to depths of penetration (as shown in Fig. 6b). If these faults indeed penetrated the surface at the time of their formation, as suggested above, their depths of penetration seen in the GPR profiles may represent approximations of past surfaces. Consequently, the combination of the results of Fig. $6 \mathrm{~b}$ with dating and with the models presented above (especially the splay process) may provide an indication of the relative level of tectonic activity as a function of average age or period.

The number of the faults as a function of average age or 
period for the grid of GPR profiles is shown in Fig. 10a. The three columns show the same trend of faulting level and the average curve reflects the average rates for the presented periods. The average curve is computed from the data collected for the period between $45000 \mathrm{ybp}$ (years before present) to the present (the GPR measurements of Evrona were not set to measure shallower than a depth of about $1 \mathrm{~m}$, therfore, the first $3600 \mathrm{y}$ were not recorded. In order to compare equal periods of $9000 \mathrm{y}$ the data for the range of $0-9000 \mathrm{y}$ presented in Fig. 10a was extrapolated and weighed from the measured range of 3600-9000 ybp).

An analysis of the results shown in Fig. 10a reveals a peak of faults at the average age of $22500 \mathrm{ybp}( \pm 1200)$, which is the center of the period of 18000-27000 ybp. The neotectonic history of the Evrona fault zone during the period of $45000 \mathrm{y}$ is shown in Fig. 10b. The peak wave of tectonic activity at the period of $18000-27000 \mathrm{ybp}$ is about $37 \%$ higher than the average tectonic activity of the entire period (the other periods are normalized to this peak).

\subsection{Recent period of reduced tectonic activity}

The recent period recorded by the GPR, during 0-9000 ybp, is caracterized by a relatively low level of tectonic activity. As can be seen in Fig. 10b, the relative level of tectonic activity of the recent period is about $70 \%$ of the average tectonic activity of the entire period and about $50 \%$ of the period of the peak wave. Combining these values and the decreasing tendency of the tectonic activity following the peak wave with surficial evidence suggest that the recent period is less active.

\section{Conclusions}

GPR images of the top $25 \mathrm{~m}$ of Evrona fault zone reveal dense sets of fractures and faults, with a variety of dip-slips, spatial orientations and depths. The apparent dips of the faults suggest that they merge at a depth of a few tens of meters. SSR observations identify a parent fault below group of faults that are detected by the GPR. According to both seismic and radar observations, a typical single active fault which is traced through the top hundred meters, changes its characteristics abruptly as it reaches a depth range of about $35-20 \mathrm{~m}$ blow the surface. It then proceeds towards the surface in a series of splays.

These observations are supported by the results of several models: The fault growth modeling and the synthetic radargram explain the series of coherent reflections observed in GPR images, suggesting that an active fault may cause a similar horizontal compaction of the stratigraphic units it penetrates, enhancing their coherency in parts of the GPR images. The damage evolution model simulates the way a parent fault branches out randomly toward the surface by the diffuse, cloud-like distribution of the micro-cracks (Fig. 7d). The branching out may occur in more than one plane. The linear shear strength decrease (LSSD) model explains the confine- ment of a parent fault in the zone of high shear strength, and the splaying in the zone of low shear strength.

An analysis of the faults detected by the GPR and dating of samples taken from trenches enable evaluating the relative level of tectonic activity of the Evrona fault zone: The recent period recorded by the GPR, during 0-9000 ybp, is characterized by a relatively low level of tectonic activity. This level is about $70 \%$ of the average tectonic activity of the entire period and about $50 \%$ of the period of the peak wave. Combining these values and the decreasing tendency of the tectonic activity following the peak wave with surficial evidence suggest that the recent period is less active.

Acknowledgements. This paper is based on parts of the Ph.D. thesis of Uri Basson which have been completed thanks to the cooperation of many people. Particular gartitude to Rivka Amit and Ezra Zilberman of the Geological Survey of Israel for the geomorphological guidance in Evrona, and to Geo-Sense - Environmental \& Engineering Geophysical Center Ltd for the GPR measurements.

\section{References}

Amit, R., Harrison, J. B. J., Enzel, Y., and Porat, N.: Paleoseismology in the southern Arava rift, U.S. Geol. Surv., Open File Rep., 94-568, 8-10, 1994.

Amit, R., Harrison, J. B. J., and Enzel, Y.: Use of soils and colluvial deposits in analyzing tectonic events - the southern Arava Rift, Israel, Geomorphology, 12, 91-107, 1995.

Amit, R., Zilberman, E., Enzel, Y., and Porat, N.: Systems of recent faults and seismic hazards in the Elat region - tour to the faults systems of Nahal Shehoret and Evrona Playa, Isr. Geol. Soc. annual meeting, Elat 1996 (in Hebrew), 1996.

Amit, R., Zilberman, E., Porat, N., and Enzel, Y.: Relief inversion in the Avrona playa as evidence of large-magnitude historical earthquakes, southern Arava valley, Dead Sea Rift, Quaternary Research, 52, 1999.

Bandel, K. and Khouri, H.: Lithostratigraphy of the Triassic of Jordan, Facies, 4, 1-23, 1981.

Bartov, Y.: A structural and paleogeographic study of central Sinai faults and domes, Ph.D. thesis: Jerusalem, Israel, The Hebrew University, 143 p. (in Hebrew, English abstract), 1974.

Bartov, Y.: Geological photomap of Israel and adjacent areas: 1:750 000 scale map, Isr. Surv., 1 sheet, 1990.

Bartov, Y., Avni, Y., Calvo, R., and Freislander, U.: The Zofar Fault, a major intra-rift feature in the Arava rift valley, Geol. Surv. of Isr. current research, 11, 27-32, 1998.

Basson, U.: Imaging of active fault zone in the Dead Sea Rift: Evrona Fault Zone as a case study. Thesis submitted for the degree of Ph.D., Tel-Aviv University, Raymond and Beverly Sackler, Faculty of Exact Sciences, Department of Geophysics and Planetary Sciences, 195 p., 2000.

Ben-Avraham, Z., Almagor, G., and Garfunkel, Z.: Sediments and structure of the Gulf of Elat (Aquaba), northern Red Sea, Sediment. Geology., Vol. 23, p. 239-267, 1979a.

Ben-Avraham, Z., Garfunkel, Z., Almagor, G., and Hall, J. K.: Continental breakup by leaky transform: The Gulf of Elat (Aquaba), Science, 206, 214-216, 1979b.

Ben-Avraham, Z.: Structural framework of the Gulf of Elat (Aquaba) - northern Red Sea., J. Geophys. Res., 90, 703-726, 1985. 
Ben-Avraham, Z.: Development of asymmetric basins along continental transform faults, Tectonophysics, 215, 209-220, 1992.

Ben-Avraham, Z. and Zoback, M.: Transform-normal extension and asymmetric basins: An alternative to pull-apart models, Geology, 20, 423-426, 1992.

Ben-Avraham, Z. and Tibor, G.: The northern edge of the Gulf of Elat, Tectonophysics, 226, 319-331, 1993.

Ben-Gai, Y., Freislander, U., and Rotstein, Y.: High resolution seismic survey in Evrona area, Isr. Inst. Pet. Res. Geophys., Rep. 836/121/92, 1993a.

Ben-Gai, Y., Rotstein, Y., and Bartov Y.: High resolution seismic reflection survey in Avrona area, Isr. Inst. Pet. Res. Geophys., Rep. 1/357/93, 1993b.

Bonilla, M. G., Mark, R. K., and Lienkaemper, J. J.: Statistical relations among earthquakes magnitude, surface ruptures length, and surface fault displacement, Bulletin of the Seismol. Soc. of America, 74, 6, 2379-2411, 1984.

Enzel, Y., Amit, R., Harrison, J. B. J., and Porat, N.: Morphologic dating of fault scarps and terrace risers in the southern Arava, Israel: Comparison to other age-dating techniques and implications to paleoseismicity, Isr. J. Earth Science, 43, 91-103, 1994.

Enzel, Y., Amit, R., Porat, N., Zilberman, E., and Harrison, J. B. J.: Estimating the ages of fault scarps in the Arava, Israel, Tectonophysics, 253, 305-317, 1996.

Freislander, U.: Semi-high resolution seismic reflection survey in Shezaf, Paran and Yotveta areas, Isr. Inst. Pet. Res. Geophys., Rep. 846/257/92, 1994.

Freislander, U.: The subsurface of the southern Arava Valley - Results from Seismic Survey, Isr. Inst. Pet. Res. Geophys., Rep. 846/257/92(c), 1995a.

Freislander, U.: The subsurface of the central Arava Valley - Results from Seismic Survey, Isr. Inst. Pet. Res. Geophys., Rep. 846/257/92(d), 1995b.

Freund, R., Garfunkel, Z., Zak, I., Goldberg, M., Weissbrod, T., and Derin, B.: The shear along Dead Sea Rift, Philos. Trans. R. Soc. London A., 267, 107-130, 1970.

Galli, P.: Active tectonics along the Wadi-Arava - Jordan Valley transform fault, J. Geophys. Res., 104, B2, 2777-2796, 1999.

Garfunkel, Z.: Generalized geological map of the Adjacent of the Southern Arava Valley, sheet 2 (in Hebrew), 1969.

Garfunkel, Z.: The Tectonics of the western margins of the southern Arava, Ph.D. thesis, Hebrew Univ., Jerusalem (in Hebrew with English abstract), 1970.

Garfunkel, Z.: Internal structure of the leaky transform (rift) in relation to the plate kinematics, in: Freund, R. and Garfunkel, Z. (Eds.): Dead Sea Rift, Tectonophysics, 80, 81-108, 1981.

Garfunkel, Z., Zak, I., and Freund, R.: Active faulting along the Dead Sea transform (rift), Tectonophysics, 80, 1-26, 1981.

Gerson, R. and Grossman, S.: Later stages in morphotectonic evolution of southern Arava Valley rift, The State of Israel, Ministry of Energy and Infrastructure, Rep. ES-1-91, 1991.

Gerson, R., Grossman, S., Amit, R., and Greenbaum, N.: Indicators of faulting events and periods of quiescence in desert alluvial fans, Earth Surface Processes and Landforms, 18, 181-202, 1993.

Gev, I.: Water level at water wells Elat-109 and Elat-106, Evrona, Southern Arava Valley, personal communication, 1999.

Joffe, S. and Garfunkel, Z.: Plate kinematics of the circum Red Sea - a reevaluation, Tectonophysics, 141, 5-22, 1987.
Johnson, A. M., Fleming, R. W., and Cruikshank K. M.: Simple broad belts of surface rupture as the common form of surface rupture produced during the 28 June 1992 Landers, California, Earthquake, U.S. Geol. Surv. Open-File Rep. 93-348, 61 p, 1993.

Johnson, A. M., Fleming, R. W., and Cruikshank K. M.: Sear Zones formed along long, straight traces of fault zones during the 28 June 1992 Landers, California, Earthquake, Bull. Seismol. Soc. America, The 1992 Landers, California, Earthquake Sequence, 84, 3, 499-510, 1994.

Lambe, T. W. and Whitman, R. V.: Soil mechanics, John Wiley, New York, 1969.

Lazarte, C. A., Bray, J. D., Johnson, A. M., and Lemmer, R. E.: Surface breakage of the 1992 Landers earthquake and its effects on structures, Bull. Seismol. Soc. America, The 1992 Landers, California, Earthquake Sequence, 84, 3, 547-561, 1994.

Lyakhovsky, V., Ben-Zion, Y., and Agnon, A.: Distributed damage, faulting, and friction, J. Geophys. Res., 102, 27 635-27 649, 1997a.

Lyakhovsky, V., Reches Z., Weinberger, R., Scott, T. E.: Non-linear elastic behavior of damaged rocks, Geophys. J. Int., 130, $157-$ 166, 1997b.

Porat, N., Wintle, A. G., Amit, R., and Enzel, Y.: Late Quaternary earthquake chronology from luminescence dating of colluvial and alluvial deposits of the Arava Valley, Isr. Quaternary Res., 46, 107-117, 1996.

Quennell, A. M.: Tectonics of the Dead Sea Rift, International Geological Congress 20th, Assoc. African Geol. Survs., 385-405, 1959.

Reches, Z., Erez, J., and Garfunkel, Z.: Sedimentary and tectonic features in the northwestern Gulf of Elat, Israel, Tectonophysics, 141, 169-180, 1987.

Shamir, G.: The November 22, 1995, Nuweiba earthquake, Gulf of Elat (Aqaba): mechanical analysis, Isr. Inst. Pet. Res. Geophys., Rep. 550/87/96, 1996.

Shtivelman, V., Freislander, U., Zilberman, E., Amit, R., and Waches, D.: High resolution seismic reflection survey at Nahal Shehoret site, southern Arava Valley, Isr. Inst. Pet. Res. Geophys., Rep. K49/146/94, Geol. Surv. Isr. Rep. TR-GSI/11/95, 1995.

Shtivelman, V., Freislander, U., Zilberman, E., and Amit, R.: Mapping shallow faults at the Evrona Playa Site using high resolution reflection method, Geophysics, 63, 4, 1257-1264, 1998.

Steinitz, G., Bartov, Y., and Hunziker, J. C.: K-Ar age determination of some Miocene-Pliocene basalts in Israel: Their significance to the tectonic of the Rift valley, Geological Magazine, 115, 329$340,1978$.

Weinberger, R., Lyakhovsky V., and Agnon A.: Damage evolution and propagation path of en-echelon cracks, in: Amadei, B., Kranz, R. L., Scott, G. A., and Smealie, P. H. (Eds.): Rock mechanics for industry, Balkema, Rotterdam, pp. 1125-1143, 1999.

Widess, M. B.: How thin is a bed? Geophysics, 38, 1176-1180, 1973.

Zak, I. and Freund, R.: Recent strike-slip movements along the Dead Sea Rift, Israel J. Earth Sci., 15, 13-37, 1966.

Zilberman, E., Amit, R., Porat, N., and Enzel, Y.: Large scale paleoearthquakes $(M>6)$ and seismic hazards along the southern Dead Sea Transform, southern Arava Valley, Israel, "ESC XXV Gen. Assem., Reykjavike, Iceland”, p. 52, 1996. 